At national, regional and global levels, collection of comprehensive health metrics is too often the poor cousin in health care and in health research. The result is a shortage of high-quality, comparable and readily accessible data.

For these reasons, the publication in The Lancet last week of the Global Burden of Disease 2010 study (GBD 2010) should be applauded. The study is an unprecedented five-year effort by hundreds of researchers in dozens of countries worldwide, who made a huge effort to track down, collate and analyse surveys, as well as published and unpublished health-care data. Led by the Institute for Health Metrics and Evaluation at the University of Washington in Seattle, they have produced a vast smorgasbord of global estimates of the burden of multiple diseases, injuries, risk factors and chronic complications (see page 322 ).

The findings capture the world's health status in impressive detail, and highlight significant trends, including how, in almost all countries, life expectancies are rapidly converging towards the long lives previously enjoyed only by the richest. The study also charts the demise of major causes of global health burden such as infectious diseases and maternal and child mortality, although these continue to blight many poorer countries, particularly in sub-Saharan Africa.

People benefit from longer lives but they are increasingly experiencing a downside. They spend many of those extra years in ill health, often with more than one illness, which creates large costs for healthcare systems. The study found that age-related illnesses include not only the usual suspects such as cancers and heart disease, but also a host of conditions that rarely kill but often disable, such as mental illness and musculoskeletal disorders.

Health-care systems and research agendas must adapt accordingly; for example, health-care providers must learn how to manage the

high costs of tackling this new disease landscape. The GBD 2010 should be required reading for health leaders and research administrators, and should lead them to re-examine how well current research portfolios match emerging trends in the burden of sickness and disease.

The GBD 2010 is far from perfect. Some of the underlying data are weak - for example, they may be scarce, unreliable or unstandardized

"The GBD 2010 should berequired reading for health leaders and research administrators." tested the GBD's assertion earlier this year that malaria killed twice as many people in 2010 as previously thought, but the study stands by its data (see Nature http://doi.org/j2s; 2012).

Such disagreements are inevitable in any complex, large-scale, international collaborative undertaking of this kind, particularly in areas where uncertainties in the data are highest. Such health metrics are also highly political, because they can affect the direction of national and international health-care and research funds, where there is much turf to fight over. But, ultimately, the findings of the GBD 2010, however imperfect, provide a robust basis and analytical framework for further research and health policies that is better than anything that went before. That its findings and methodologies will be challenged and debated in the months and years to come is not only healthy, but how science works. The way forward is to rework and build on the foundations that have been laid. .

\title{
Head of the line
}

\section{Japanese scientists deserve support in their bid for the next big collider.}

\section{$\mathrm{T}$} he International Linear Collider (ILC) is, literally, a pipe dream in the minds of physicists. The proposed 31-kilometre-long superconducting machine is the heir apparent to the Large Hadron Collider (LHC) - the world's most powerful particle accelerator - at CERN, Europe's particle-physics laboratory near Geneva, Switzerland. For now, the ILC remains a paper study, but particle physicists would like to see it built so that they can probe ever more fundamental questions about the nature of matter.

During the best of times, large, multibillion-dollar facilities such as the ILC take decades of planning and political preparation, and these are not the best of times. As the world's governments struggle through the worst financial crisis in a generation, the prospects for any project of this scale are daunting to say the least.

But there is one possibility: Japan. The island nation has yearned for a big international project such as the ILC, and it very nearly got one in 2005, but narrowly lost out to France on the giant ITER fusion project. Politicians and physicists there who had backed the ITER bid were dejected but determined, and they have formed a strong, crossparty political group to bring the ILC to Japan.

This coalition has worked diligently for years to promote a Japanese bid, but two developments make it even more likely to happen. First, on 11 March 2011, a devastating earthquake and tsunami rocked the Tohoku region of Japan. Reconstruction yen have been flowing since, and a science city being built in the region has emerged as a possible engine for development (a second site for the collider is also on the table, in the southern region of Kyushu). Second, the discovery of the Higgs boson at CERN in July provides the ILC with a scientific target - even running at less than full energy, the ILC could provide a detailed study of the new particle.

Taking account of these two events, politicians in both of Japan's major political parties seem increasingly interested in an ILC-type project. It even formed part of the party platform of the Liberal Democratic Party, which won last weekend's parliamentary elections. Moreover, Japan is technically ready for the project. A slew of high-profile experiments built in the 1990s and 2000s show that it has the skill and industrial know-how to take on an advanced accelerator. It has also been leading ILC research and development in several areas, including crucial work on how to focus the beams.

But Japan can't do it alone. It will need expertise, funds and in-kind contributions from around the globe. Europe seems to be coming around to the idea. After all, Japan has contributed to CERN, and the lab is busy with its own collider. In the United States, support is considerably softer. The main US laboratory, Fermilab in Batavia, Illinois, recently lost its main accelerator and has begun an ambitious neutrino programme in its stead. Budgets are not sufficient to support that, the ongoing LHC work and the ILC.

US and European scientists should throw their support behind the ILC project. For the forward-thinking Europeans, this means a clear commitment to the parts and manpower they might be able to supply. For the Americans, it would probably require a willingness to slow the neutrino programme. That may be hard for them to swallow but, deep down, US physicists know that participation in the ILC is the only real option if the nation is to remain at the vanguard of particle physics.

Statements of support from overseas will not guarantee that the ILC will go ahead. Japan's opaque government will still have to debate the $\rightarrow$ NATURE.COM To comment online, click on Editorials at: go.nature.com/xhunqv programme's merits internally and come up with a process for committing to its construction. But an early show of support could give the collider the push it needs to get under way. That would be a great victory for Japan, and the world. 